\title{
A construção do conhecimento na Escola Família Agrícola da Serra Gaúcha e das Casas Familiares Rurais do Rio Grande do Sul
}

The construction of knowledge at the Family Agricultural School of Serra Gaúcha and Rural Family Houses in Rio Grande do Sul

Aline Guterres Ferreira José Vicente Lima Robaina

Alberto Bracagioli Neto José Geraldo Wizniewsky

Resumo: Os cursos de licenciatura em Educação do Campo são resultados da demanda dos movimentos sociais do campo. Esses transcorrem em tempos e espaços diferentes das licenciaturas tradicionais, o que permite maior imersão dos licenciandos nas Escolas do Campo. Este artigo possui objetivo de analisar as percepções dos estudantes das instituições que fazem parte dos Centros Educativos Familiares de Formação por Alternância (CEFFA's), sobre a diversidade de produção de alimentos e o sistema educacional em que vivem. Para isso, adota-se uma abordagem qualitativa de pesquisa, a observação participante e o uso de questionário com perguntas abertas e discursivas para a coleta de dados. Os resultados demonstram a necessidade de metodologias educacionais inovadoras que promovam uma maior integração entre as Escolas do Campo e as comunidades onde estão inseridas.

Palavras-chaves: Educação do campo, Aprendizagem, Pedagogia da alternância, Desenvolvimento rural.

Abstract: Undergraduate courses in Rural Education are the result of the demand of rural social movements. These take place in times and spaces that are different from traditional degrees, which allows greater immersion of graduates in the Schools of the Field. This article aims to analyze the perceptions of students from institutions that are part of the Family Educational Centers for Alternation Training (CEFFA's), about the diversity of food production and the educational system in which they live. For this, a qualitative research approach is adopted, participant observation and the use of a questionnaire with open and discursive questions for data collection. The results demonstrate the need for innovative educational methodologies that promote greater integration between the Schools of the Field and the communities where they operate. Keywords: Rural education, Learning, Alternation pedagogy, Rural development.

\section{Introdução}

Este artigo é baseado no trabalho de conclusão de curso da graduação em licenciatura em Educação do Campo - ciências da natureza da Universidade Federal do Rio Grande do Sul (UFRGS). O curso de licenciatura na UFRGS tem como preceito a Pedagogia da Alternância (NOSELLA, 2014) onde os estudantes alternam entre períodos de tempo e espaço diferentes. O Tempo Universidade (TU) é desenvolvido na Faculdade de Educação e Agronomia e o 
Tempo Comunidade (TC) desenvolvido nas Escolas do Campo, onde são trabalhados projetos com estudantes, professores e a comunidade em que a escola está inserida. Também é possível desenvolver os estágios "escolar e não escolar" estando os projetos, preferencialmente, relacionados com o trabalho de conclusão de curso (TCC) dos licenciandos.

No final dos anos 90 e na primeira década do século 21, foram criados diversos programas e políticas públicas em resposta a demanda dos movimentos sociais populares do campo por uma educação mais justa, contextualizada e que respeitasse os saberes do campo. Os cursos de licenciatura em Educação do Campo surgem com um novo referencial de educação e possuem uma perspectiva pedagógica metodológica inovadora, fruto das demandas e da pressão dos movimentos e organizações sociais, bem como um incentivo a políticas públicas de créditos e financiamentos para as populações esquecidas.

A perspectiva adotada nestes cursos é de que o professor não é detentor do conhecimento e seus estudantes, tábulas rasas (BORDENAVE, 1977). Entende-se a educação como uma construção social, histórica e ambiental e que todos são (co)responsáveis pela educação. O grande mestre da educação popular, Paulo Freire, Patrono da Educação Brasileira, já dissertava nessa perspectiva.

A educação constitui-se em um ato coletivo, solidário, uma troca de experiências, em que cada envolvido discute suas ideias e concepções. A dialogicidade constitui-se no princípio fundamental de relação entre educador e educando. O que importa é que os professores e os alunos se assumam epistemologicamente curiosos (FREIRE, 1988, p. 96).

A licenciatura também possui como objetivo problematizar a agricultura convencional, desprovida de conservação e preservação ambiental, cultural e econômica. A autora Roseli Caldart (2012, p. 19) descreve que "A perspectiva da educação do campo é exatamente a de educar este povo, estas pessoas que trabalham no campo, para que se articulem, se organizem e assumam a condição de sujeitos de seu destino.".

De acordo com o Projeto Pedagógico do Curso na UFRGS (PPCLedoc, 2013), este propõe atender a uma nova demanda, as populações do campo, que 
historicamente lutam por uma educação diferenciada de qualidade, que respeite as especificidades da vida neste contexto. Destaca-se que o curso traz um novo modelo de formação alicerçado na interdisciplinaridade, desenvolvido nas práticas dos docentes e discentes, nos TU e TC. Outro diferencial é a formação por área de conhecimento, a ciência da natureza, única na UFRGS, a qual está associada a uma proposta de Alternância.

O projeto pedagógico do curso ainda define os objetivos e campos de atuação do Educador do Campo, "formação inicial de educadores para atuarem na Educação Básica do Campo e em instituições que desenvolvam modalidades de assistência técnica e extensão rural." (PPCLedoc, 2013, p. 08). Ainda, formar educadores/as para docência interdisciplinar em Ciências da Natureza e contribuir na construção e expansão da Educação Básica no Campo com qualidade na dinâmica social em que as pessoas estão inseridas. (PPCLedoc, 2013).

As experiências educacionais aqui estudadas tiverem início na década de 30 na região sudoeste da França. Quando agricultores familiares juntamente com entidades religiosas e do campo se reuniram para construir uma alternativa de formação para os jovens do meio rural continuarem seus estudos, sem desvincular-se do trabalho e da vida no campo. Assim foi proposto o movimento da alternância como um modo de organização do processo educativo capaz de entrelaçar as aprendizagens do trabalho agrícola realizado nas propriedades familiares e a formação escolar realizada na Paróquia, em internato. As autoras Sobreira e Silva (2014, p. 215) dissertam sobre, "Começou a se esboçar, assim, um dos traços fundamentais do projeto de formação de jovens rurais, posteriormente denominado de Maisons Familiares Rurales, que alternava os tempos e espaços do trabalho prático na propriedade agrícola e da formação teórica na escola.".

No Brasil essas experiências educacionais também nascem em períodos históricos conturbados. No início de 1969, são criadas as primeiras Escolas Famílias Agrícolas no Estado do Espírito Santo sob coordenação da congregação Jesuíta com inspiração nas Maisons Familiares Italianas. Em meados da década de 1980 teve início a implementação das primeiras Casas 
Familiares Rurais nos Estados de Alagoas e Pernambucos. Essas instituições inspiradas mais diretamente ao modelo Francês, (SOBREIRA E SILVA, 2014).

Ainda com as autoras destacam a influência das ideias de Paulo Freire no nascimento da Alternância no Brasil, muitos são os estudos que discutem as aproximações da Pedagogia da Alternância e a Pedagogia de Paulo Freire, seja sua criação fora do universo acadêmico e/ou do sistema formal de ensino, a vinculação delas aos movimentos sociais e a concepção dos povos do campo como agentes históricos e transformadores da realidade (MÂNFIO 1999 apud SOBREIRA E SILVA, 2014). Destacam-se nesse um dos diferenciais das experiências Latino Americanas das pioneiras do continente europeu.

Visto as singularidades dessas experiências educacionais, através desta pesquisa pretende-se responder a seguinte questão: quais as estratégias educativas que contribuem para a Construção do Conhecimento nas escolas que desenvolvem trabalhos orientados pelo referencial da Educação do Campo, cooperando para a formação do sujeito crítico e transformador e promotor do desenvolvimento rural? Foi tomado como universo empírico o Estado do Rio Grande do Sul, no que abrange as Escolas do Campo nas esferas de Escolas Famílias Agrícolas (EFA) e Casas Familiares Rurais (CFR). Mais especificamente, a Escola Família Agrícola da Serra Gaúcha, na qual foi realizado o estágio escolar de um dos autores do artigo, e na Casa Familiar Rural de Frederico Westphalen, onde ocorreu o Curso de Formação de Monitores dos CFR's Gaúchos. Segundo Pessotti (1978), essas instituições são escolas que visam construir uma nova forma de fazer educação para os jovens do campo. Estas constituem os Centros Educativos Familiares de Formação por Alternância (CEFFA's).

Este trabalho tem como objetivo descrever as aproximações e distanciamentos das percepções que os estudantes possuem das agriculturas "alternativas" e do modelo agrícola convencional, também, as compreensões do sistema de ensino que vivenciam, no que tange a Pedagogia da Alternância e os Instrumentos Pedagógicos que dela fazem parte. Ainda, são realizadas analises das ferramentas educacionais dessas instituições para que se concretize a 
transformação do meio e a formação cidadã, a partir dos referenciais da Educação do Campo.

\section{Metodologias}

Toma-se por base as escolas localizadas no meio rural do Rio Grande do Sul, mais especificamente as que compunham a rede CEFFA's. Destas, participaram da pesquisa a Escola Família Agrícola da Serra Gaúcha, em Caxias do Sul, durante a experiência da disciplina do Estágio de Docência II - Ciências no Ensino Médio, e a Casa Familiar Rural de Frederico Westphalen, onde ocorreu o Curso de Formação de Monitores, dessas instituições.

Adota-se uma abordagem qualitativa de pesquisa, na qual é possível analisar a relação entre o mundo real e o sujeito de forma dinâmica, considerando a existência de ligações indissociáveis entre "o mundo objetivo e a subjetividade do sujeito", questões que os números não comportam (SILVA; MENEZES, 2001).

Como método de pesquisa, utilizamos a prática da observação participante junto ao um diário de campo para registro, segundo Gil (2008) uma das vantagens que observação apresenta é que os fatos são percebidos diretamente, sem qualquer intermediação, reduzindo a subjetividade do processo de investigação social. Ainda, a aplicação de questionário com questões abertas e discursivas. Também foi realizada analise de bibliografia e dos dados secundários sobre o referencial do universo empírico das instituições de ensino que sediaram a pesquisa. E o acompanhamento dos eventos escolares, tais como, saídas de campo, formação de professores, visitas pedagógicas e assembleias (reuniões pedagógicas).

O desenvolvimento desta pesquisa foi dividido em três etapas. A primeira constitui na pesquisa documental, mapeamento a construção do referencial teórico; a segunda etapa constitui-se na pesquisa de campo e; no terceiro momento foi realizada a organização e interpretação dos dados, e por último a escrita do artigo. 
Após leituras e estudos dos referenciais da Educação do Campo e das pesquisas referentes a essas instituições de ensino, é planejada a saída de campo para a coleta de dados.

A segunda fase da pesquisa foi desenvolvida no segundo semestre de 2018, durante a disciplina do estágio de docência, realizado na Escola Família Agrícola da Serra Gaúcha no município de Caxias do Sul. As técnicas de pesquisa utilizadas durante as aulas da docência e da vivência escolar foram a observação participante e o questionário com perguntas abertas e discursivas.

Também, nesse mesmo período, ocorreu o Curso de Formação de Monitores na Casa Familiar Rural de Frederico Westphalen, neste mesmo município. Nesta experiência, estavam presentes os monitores, gestores e funcionários de todas as Casas Familiares Rurais do Estado do RS.

O diário de campo acompanhou todos esses momentos, para o registro das observações, questionamentos e reflexões. Como nos traz o autor Barros e Lehfeld (1994, p. 21), "observar significa aplicar atentamente os sentidos a um objeto para de ele adquirir um conhecimento claro e preciso. A observação tornase uma técnica científica a partir do momento em que passa por sistematização, planejamento e controle da objetividade.".

Para a coleta de dados, ao final do estágio, foi aplicado um questionário com perguntas abertas e discursivas para os estudantes da segunda série (32 estudantes) e terceira série (11 estudantes) do ensino médio, num total de 43 estudantes. Para os quais foram ministradas aulas de ciências da natureza e ciências agrárias, durante o semestre. Os nomes desses estudantes foram preservados nesta pesquisa e suas respostas foram referenciadas apenas com iniciais nas discussões deste artigo. A partir do questionário aplicado durante a aula, foi possível coletar informações acerca do que "as pessoas sabem, creem, esperam, sentem ou desejam, pretendem fazer, fazem ou fizeram, bem como acerca de suas explicações ou razões acerca das coisas precedentes" (GIL, $2008, p .117)$. As perguntas do questionário que guiaram as respostas dos estudantes foram as seguintes:

Qual sua compreensão de Agricultura Orgânica, Biodinâmica, Agroecológica e Convencional? 
Como é desenvolvida a Pedagogia da Alternância? Quais instrumentos mais gosta? E quais tem maior dificuldade? Por quê?

Para que serve os Instrumentos Pedagógicos?

É associado ao Sindicato dos Trabalhadores Rurais? Participa de suas atividades?

Os estudantes tiveram um período de 50 minutos para responder as perguntas, dentro de sala de aula, com muita tranquilidade e liberdade nas respostas, se assim o quisessem ou não responder.

A terceira e última fase da pesquisa foi a análise e tabulação dos dados, pelo método da Triangulação. Segundo Marcondes e Brisola (2014, p. 204) o método de análise por triangulação é "pautado na preparação do material coletado e na articulação de três aspectos para proceder à análise de fato", a saber.

Sendo que o primeiro aspecto se refere às informações concretas levantadas com a pesquisa, quais sejam, os dados empíricos, as narrativas dos entrevistados; o segundo aspecto compreende o diálogo com os autores que estudam a temática em questão; e o terceiro aspecto se refere à análise de conjuntura, entendendo conjuntura como o contexto mais amplo e mais abstrato da realidade. A articulação desses três aspectos, para proceder à análise (MARCONDES E BRISOLA, 2014, p. 204).

As respostas dos estudantes foram agrupadas pelas perguntas guias, e dado o destaque para as mais representativas em repetição, com base no referencial teórico já estabelecido na primeira fase da pesquisa e a comparação com estudos anteriores. Visando assim, identificar quais percepções os estudantes da segunda e terceira série do ensino médio da Escola Família Agrícola da Serra Gaúcha possuem das agriculturas "alternativas" ao modelo agrícola convencional e também os pontos positivos e negativos da Pedagogia da Alternância e dos Instrumentos Pedagógicos que dela fazem parte.

Bem como a análise dos referenciais estudados no Curso de Formação de Monitores, tais como Trevisan (2018), que conduzem o trabalho dessas instituições de ensino. 


\section{As Aprendizagens pelos Caminhos na Escola Família Agrícola da Serra Gaúcha}

As Escolas Famílias Agrícolas e Casas Familiares Rurais, desde sua origem, possuem entre os seus princípios, o desenvolvimento do meio visando o crescimento da comunidade rural sem prejuízos ambientais, econômicos e sociais para a população e a natureza. Para concretização do desenvolvimento rural é necessário um sistema de produção alternativo ao modelo convencional respeitando o equilíbrio entre produção e conservação ambiental, aliado ao desenvolvimento social e econômico.

Essas instituições desenvolvem processos de aprendizagem, objetivando sistemas de produção que possuam menores impactos negativos para o ambiente e para a sociedade, buscando, desenvolvimento em suas múltiplas dimensões. No período do estágio de docência na EFA Serra Gaúcha, teve-se a oportunidade de acompanhar em saídas de campo e visitas pedagógicas, que são Instrumentos da Pedagogia da Alternância, esses processos de aprendizagens.

Em agosto de 2018, foi realizada uma visita ao Assentamento Capela e a Agroindústria de Citros, no município de Nova Santa Rita, RS. Onde os estudantes puderam conhecer a maior produção de arroz agroecológico da América Latina e ainda conhecer a história dos Assentados da Reforma Agrária do Movimento dos Trabalhadores Rurais Sem Terra (MST). Também tiveram contato com algumas práticas da Agricultura Biodinâmica e sistemas de produção orgânicos. Todas essas agriculturas "alternativas" ao modelo convencional foram muito debatidas nas aulas da EFA, no preparatório à saída de campo e no retorno das visitas pedagógicas, com auxílio de artigos científicos, reportagens técnicas e jornalísticas, além de circulares técnicos das instituições de pesquisas agropecuárias.

Este cenário serviu como base para posterior aplicação do questionário da pesquisa com intuito de capturar quais as compreensões dos estudantes sobre essas diversas agriculturas. As análises por triangulação, trazem uma seleção das respostas dos estudantes que mais representaram o grande grupo, junto aos referenciais teóricos estudos e o comparativo com pesquisas 
anteriores e a conjuntura. Para a Agricultura Orgânica, os estudantes envolveram suas respostas em práticas agrícolas sem a presença de agrotóxicos, adubos químicos e a utilização de insumos produzidos dentro da propriedade, além de uma maior segurança na saúde humana e ambiental. Como descrito nas respostas a seguir.

Agricultura Orgânica busca uma melhor qualidade da produção, com o uso de insumos naturais, procurando a harmonia entre o meio ambiente e a saúde. Estudante $\mathrm{M}$.

...utiliza de práticas sem a presença de agrotóxicos, buscando outros meios de produção, visando à saúde de produtores e consumidores. Estudante $\mathrm{K}$.

Os estudantes apresentaram entendimentos semelhante ao conceito de Caporal e Petersen (2012), quando esses trazem que a agricultura orgânica produz energia, fibras e alimentos por um modo de produção que conserva e incrementa a biodiversidade ambiental.

Quando questionados sobre Agricultura Agroecológica, suas respostas variaram entre as práticas já vivenciadas na EFA Serra Gaúcha, como o cultivo de uma Agrofloresta e os aprendizados das visitas pedagógicas e saídas de campo. Podemos observar a baixo.

Agricultura Agroecológica é um sistema de produção alimentício que visa à produção viavelmente ambiental (sem agredir o meio ambiente), mantendo o equilíbrio entre produção e natureza. Estudante D.

...trata-se de aproveitar todas as essências e saberes populares. Estudante L.

Baseia-se em uma agricultura sustentável, com técnicas que respeitam o meio ambiente e devolvem a fertilidade do solo. Estudante D.

A seguir, demonstra-se um comparativo dessa pesquisa com outra realizada na Escola Família Agrícola de Santa Cruz do Sul (EFASC), deste município no RS, em 2014. Pode-se perceber semelhanças nas compreensões dos estudantes referentes ao conceito de Agroecologia. Em 2014 os estudantes entendiam como “...uma Ciência sem a produção com agrotóxicos, insumos químicos ou sintéticos, exteriores a propriedade." Mas adicionavam a este 
conceito, as questões sociais e de diversidade de conhecimentos que esse sistema requer, tais como.

...Ciência da Agroecologia como um estilo de vida, onde você se beneficia e beneficia a natureza, sem prejudica-la. [...] a importância dos conhecimentos empíricos e científicos e a sua igualdade de importância para o desenvolvimento, seja ele social, produtivo e econômico, também podemos destacar o equilíbrio produtivo e ambiental dentro da propriedade, evitando os desperdícios de recursos naturais e o consumismo desordenado. A diversificação da propriedade também foi ressaltada na fala dos educandos, bem como a responsabilidade de preservação e conservação que deve ser conjunta com toda a comunidade, respeitando os ciclos da natureza. (FERREIRA, 2014, p. 83).

Compreende-se que o conceito de Agroecologia deriva muito da perspectiva que cada ator, seja este acadêmico, integrante de movimentos sociais, cooperado, agricultor familiar, empresário, entre outros. Essa diversidade de conhecimentos caracteriza a interdisciplinaridade dessa ciência e sua multiplicidade, mas todas essas possuem alguns princípios comuns. Para este artigo utiliza-se a perspectiva de Toledo (2012) apud Le Coq. et al., (2017), quando este faz um comparativo do Modelo Agroecológico com o Modelo Agroindustrial.

Quadro 01: Contraste entre o modelo agroecológico e o modelo agroindustrial.

\begin{tabular}{|c|c|}
\hline Modelo Agroecológico. & Modelo Agroindustrial. \\
\hline $\begin{array}{c}\text { - Ciência da complexidade, multi e } \\
\text { interdisciplinar. } \\
\text { - Autossuficiência tecnológica. } \\
\text { - Diálogo de saberes. } \\
\text { - Pequena escala. } \\
\text { - Uso diversificado. } \\
\text { - Baseada diretamente ou indiretamente em } \\
\text { fontes naturais de energia: solar, eólica, } \\
\text { hidráulica, animal, humana. } \\
\text { - Reciprocidade com os processos naturais. }\end{array}$ & $\begin{array}{c}\text { - Ciência especializada, analítica e } \\
\text { reducionista. } \\
\text { - Dependência tecnológica. } \\
\text { - Domínio epistemológico. } \\
\text { - Grande escala. } \\
\text { - Uso especializado. } \\
\text { - Baseado em fontes de energia fóssil: } \\
\text { petróleo e gás. } \\
\text { - Controle ou domínio dos processos } \\
\text { naturais. }\end{array}$ \\
\hline
\end{tabular}

Fonte: Toledo (2012), apud Le Coq. et al., (2017). Tradução livre do autor.

Destaca-se do quadro, o item Diálogo de Saberes em contraponto ao Domínio Epistemológico, onde se reafirma que a construção do conhecimento deve ser baseada na coautoria entre os conhecimentos tradicionais e os científicos e que esse pode ser desenvolvido pelos métodos entre "campesino- 
a-campesino ou científico-a-campesino-a-científico", segundo a revisão que Le Coq et al. (2017), semelhante ao movimento da Pedagogia da Alternância.

Em relação à Agricultura Biodinâmica, segundo Jovchelevich (2007), essa agricultura possui como um dos princípios a utilização dos ritmos astronômicos nas práticas agrícolas e a revalorização do conhecimento popular sobre uso das fases da lua na agricultura e ainda amplia, incorporando os outros ritmos da lua e movimento dos planetas relacionados com as atividades agrícolas em geral. Os estudantes apresentaram uma compreensão próxima ao conceito. A seguir.

Agricultura Biodinâmica é baseada nos astros, na lua, nas estrelas, abrange diversos manejos com os meses do ano. Estudante J.

...que visa produzir alimentos a partir de insumos orgânicos e preparados de resíduos animais. Estudante D.

Visto que, foi trabalhado com os estudantes em aula o artigo Viticultura Biodinâmica na Serra Gaúcha (2016), um projeto piloto da Federação das Cooperativas Vinícolas do RS. Onde apresentam os conceitos e as práticas da agricultura biodinâmica no cultivo de uva, principal produção agrícola dos estudantes. Portanto, suas respostas sintetizaram as concepções das literaturas estudadas e as informações apreendidas nas saídas de campo.

A seguir é questionado sobre o modelo agroindustrial de agricultura, o sistema convencional de produção. Como visto com Toleto (2012), apud Le Coq. et al., (2017), este sistema tem como base, entre outras, a dependência tecnológica e como principal fonte de energia fóssil, o petróleo e o gás, demonstrando assim a insustentabilidade da produção. As respostas dos estudantes trazem uma conscientização dos impactos negativos nos produtos e nos agricultores/consumidores, porém justificam pela maior produtividade, retorno financeiro e praticidade, além da utilização de tecnologias por maquinários agrícolas.

Agricultura convencional trabalha com a utilização de agrotóxico e isso facilita o trabalho dos agricultores, e não visa à saúde, mas tem produtores que cuida e usam da forma certa. Estudante $\mathrm{H}$.

...uso de agrotóxico, implementos agrícolas e não preserva natureza, meio ambiente. Estudante $\mathrm{E}$. 
Visa à produtividade. Prejudica o meio ambiente, o solo, o agricultor e o consumidor final. Permitindo o uso de químicos. Estudante G.

Sistema que produz alimentos a partir de defensivos agrícolas e insumos químicos, com objetivo de aumento do poder econômico. Estudante D.

É uma forma facilitada de produção, porém compromete a saúde das pessoas e do meio ambiente. Estudante Z.

As respostas dos estudantes demonstram um grande desafio para essas instituições de ensino, na reflexão e quebra do paradigma da produção convencional em detrimento aos modelos de agricultura mais sustentáveis.

A seguinte questão foi relativa à compreensão sobre a Pedagogia da Alternância. Todos os estudantes que responderam essa questão, trouxeram o movimento que realizam de alternar, da sessão escolar para a sessão familiar no decorrer do ano letivo, restritos apenas ao regime de alternância. Aos que completaram suas respostas, destaca-se a aplicabilidade dos conhecimentos adquiridos na sessão escolar em suas propriedades na sessão familiar, também a relação teoria e prática nesses dois diferentes territórios e a possibilidade de não perder o contato com seus familiares e comunidade de origem. Como está apresentado a seguir.

A Pedagogia da Alternância consiste na integração entre a teoria e a prática, onde uma semana temos a prática, convivência e aprendizado em casa e outra trocando conhecimento e aprendendo teoria na escola. Estudante D.

...ela visa fazer com que o jovem possa estar uma semana na escola convivendo com colegas e aprendendo na teoria, e uma semana em casa convivendo com a família. Estudante A.

...é ficar uma semana na escola estudando aulas teóricas e também algumas práticas, e uma semana em casa usufruindo do seu conhecimento. Estudante C.

As autoras Sobreira e Silva (2014), identificam na gênese da Pedagogia da Alternância um movimento dialético que, partindo da realidade e da experiência de vida e trabalho dos jovens agricultores, foi paulatinamente se consolidando no diálogo e na fundamentação teórica, revelando assim o movimento da práxis, que se realiza na busca permanente de articulação entre ação e reflexão. Próximo a compreensão que os estudantes apresentaram. 
Para efetivar a Pedagogia da Alternância, os Instrumentos Pedagógicos devem ser executados com responsabilidade, coerência e integração dos territórios de aprendizagens dos estudantes, escola(s) e família/comunidade. Deste modo, foi questionada aos estudantes sua compreensão dessas ferramentas, se sentem alguma dificuldade no desenvolvimento destes e as facilidades que trouxeram para suas aprendizagens. Os nove estudantes que responderam essa questão, trouxeram suas diversas experiências e as relações particulares com esses instrumentos, aqui vamos descrever, algumas dessas percepções.

Os Instrumentos Pedagógicos servem para acompanhar os estudos e as práticas dos alunos na escola e em casa. Estudante $\mathrm{X}$.

...influenciam na nossa formação pessoal quanto na profissional. Estudante $\mathrm{Y}$.

Serve para gerar conhecimento para o estudante de uma maneira que fixa o conteúdo com mais facilidade. Estudante $D$.

...para termos uma melhor organização das tarefas propostas, nos trazem uma realidade do dia a dia, em nossas formas de estudos na EFA. Estudante W.

Tendo em vista que os Instrumentos Pedagógicos são as ferramentas que consideramos para efetivação da Construção do Conhecimento da Pedagogia da Alternância nessas Escolas do Campo, a sua execução deve possibilitar o diálogo entre os conhecimentos técnicos científicos dos professores/monitores e os conhecimentos locais, do cotidiano e da prática dos estudantes. Permitindo a esses, suas famílias e a escola compartilhar e formar "novos" conhecimentos, a partir de uma (re)construção, ressignificação e reflexão das aprendizagens que vivenciam. Como podemos destacar a seguir.

Os instrumentos pedagógicos são as ferramentas que permitem a partilha e a elaboração dos conhecimentos advindos da família/comunidade para a escola, que tem por obrigação a construção de uma reflexão com os estudantes, que retornam essa elaboração para a sua família/comunidade, em muitos casos experimentando esse "novo" conhecimento na propriedade. Os instrumentos pedagógicos quando vivenciados de forma intensa, acabam instrumentalizando os estudantes para uma ação concreta, seja de fórum íntimo/individual ou na construção do seu intelecto e personalidade evidenciados pelas 
suas práticas sociais na família/comunidade. (COSTA, 2012, p. 170).

Segundo Nascimento (2005) as finalidades desempenhadas pelos Instrumentos Pedagógicos da Pedagogia da Alternância utilizam-se a fim de possibilitar a integração da escola com a família e a comunidade. Os Instrumentos Pedagógicos são caminhos eficazes para integrar teoria e prática, e família e escola, tendo como finalidade primordial a formação integração do jovem e adolescente proveniente, no caso brasileiro, em sua ampla totalidade, do meio rural que é o seu local real e concreto.

Os estudantes responderam no questionário, qual o Instrumento Pedagógico que mais apreciam. Considera-se os Instrumentos apontados por cada estudante como sendo o de maior importância para sua aprendizagem, pois este contribui fundamentalmente para a construção do conhecimento, uma vez que possui valor afetivo agregado. O movimento da Alternância foi o mais citado, juntamente com o Estágio de Vivência, destacado por nove estudantes cada, justificados a seguir.

A alternância, pois é uma ferramenta inovadora que permite o vínculo da família e dos estudos. Estudante $\mathrm{K}$.

Eu gostei muito do Estágio de Vivência, assim podemos viver a realidade de outros colegas. Estudante $\mathrm{G}$.

Eu gosto mais do instrumento Estágio de Vivência, que nos abre portas para conhecer novas realidades e culturas, enriquecendo nossas vivências. Estudante D.

Segundo a Cartilha dos Instrumentos Pedagógicos da Pedagogia da Alternância da EFA Serra Gaúcha, livreto este que é disponibilizado às famílias dos estudantes no seu ingresso à escola para conhecimento das responsabilidades dos filhos e responsáveis nessa nova vivência escolar. 0 Estágio de Vivência é definido assim.

É uma atividade programada para que os estudantes permaneçam uma semana na casa do colega e receba o mesmo na semana seguinte em sua casa. Serve para a troca de experiências, saberes e vivências entre os estudantes da EFA. Participam Estudantes, familiares e comunidade. Acontece uma vez ao ano e tem a duração de duas semanas. A família fica responsável por acolher, acompanhar e instruir o colega de seu filho nas atividades desenvolvidas no dia-a-dia na propriedade. 
E cabe aos jovens a elaboração de relatório final sobre os aprendizados adquiridos no estágio de vivência bem como a atividade de retorno proposta. (CIPPA EFASerra Gaúcha, 2013, p. 12).

Já a Alternância, o movimento que os estudantes vivem entre uma semana na Sessão Familiar (na propriedade da família e comunidade) e outra semana na Sessão Escolar (interno na escola), sempre foi bem avaliada pelos estudantes. No trabalho desenvolvido por Ferreira (2014), também é possível identificar que os estudantes consideraram essa dinâmica de ensino positiva a sua aprendizagem e a diminuição do êxodo rural. Como podemos ver a seguir.

\begin{abstract}
A maioria dos educandos destacou a importância desta metodologia para não perder o vínculo com a família e a propriedade e o aumento dos conhecimentos das mesmas, bem como a construção do conhecimento realizado pelos Monitores, educandos, familiares e comunidade, resgatando e respeitando o conhecimento dos pais e avós (antepassados) e aliando as teorias que aprende na escola. (FERREIRA, 2014, p. 73).
\end{abstract}

Diversos outros Instrumentos Pedagógicos foram citados pelos estudantes, dos mais simples como o posicionamento das carteiras escolares em formato de círculo, que segundo a estudante A “...o que mais gosto é o esquema de sala de sentarmos em roda, para mim isso facilita a comunicação com os colegas." até os instrumentos que possuem maior complexidade pedagógica como as visitas pedagógicas e saídas de campo, os quais serviram de base à essa pesquisa.

A questão seguinte traz os instrumentos que os estudantes mais relataram possuir dificuldades. O Plano de Estudos e Projeto Profissional do Jovem (PPJ) apareceram nesse item com maior índice, mas não deixaram de estar presente na questão anterior, demonstrando assim a particularidade da relação dos estudantes com os Instrumentos Pedagógicos e a homogeneidade do grau de complexidade desses.

O instrumento que desponta para os estudantes da terceira série é o Caderno da Realidade, justificam que sua organização não é de forma fácil e seus pais apresentaram dificuldades de acompanhar no decorrer dos anos. Já para os estudantes da segunda série, o PPJ foi apontado como o instrumento de maior dificuldade, mesmo que ainda não tenham iniciado a sua redação. O PPJ 
é o trabalho final do ensino médio, redigido apenas no último ano escolar, mas sua sistematização já inicia nos primeiros planos de estudos dos estudantes. $O$ conceito que o orienta é o seguinte:

É um projeto elaborado pelo estudante que é acompanhado pela família e auxiliado pela EFA. Tem por objetivo encaminhar o jovem para a profissionalização do trabalho rural, no sentido de melhorar sua renda e a qualidade de vida da família. Participam o Estudante, família, Escola, comunidade e parceiros. Tem por objetivo despertar no jovem o protagonismo sobre seu trabalho a partir de uma intervenção na sua propriedade com conhecimento técnico no sentido de melhorar sua renda e a qualidade de vida da família. Acontece desde o início de seus estudos na EFA, o estudante é incentivado a realizar as pesquisas dos Planos de Estudos com vistas à elaboração do PPJ. A redação final do PPJ é realizada durante o $3^{\circ}$ Ano seguida pela defesa e avaliação por banca composta por tutores, monitores e técnicos. O sucesso do PPJ dependerá do grau de compromisso do jovem e da família durante a realização dos Planos de Estudo. (CIPPA EFASerra Gaúcha, 2013, p. 13).

As justificativas que permearam essas dificuldades discorrem pelo tempo gasto na dedicação aos estudos que poderiam estar trabalhando na propriedade familiar e também pela falta de comprometimento dos colegas, quando destacado os Coletivos de Limpeza da Escola. Essas dificuldades são diagnosticadas pela equipe de Monitores/Professores e a Gestão Escolar, tanto na Assembleia Geral (reunião) com os pais e responsáveis, nos Cadernos de Acompanhamento, como nos acolhimentos individuais realizadas pelos Tutores com os seus orientandos (estudantes).

O Desenvolvimento do Meio, a nível social, ambiental, econômico, humano, político, é um dos Pilares Fins da Pedagogia da Alternância, junto com a Formação Integral do jovem por um projeto pessoal de vida. Possui como Meios para chegar a esses Fins a Alternância, como uma metodologia pedagógica adequada junto com a Associação Local formada pelos pais, famílias, profissionais e instituições. Essas instituições podem ser públicas ou privadas, onde se aliam em prol ao desenvolvimento rural sustentável, solidário e cooperativo, e, perante isso, nos propomos a analisar se os estudantes ou suas famílias são sócios dos Sindicatos dos Trabalhadores Rurais (STR) de suas regiões e se já participaram de alguma atividade promovida por esta instituição. 
Infelizmente tivemos um total de 19 estudantes que não são sócios e nem suas famílias do STR, dois estudantes são associados no Sindicato Rural Patronal e apenas 11 estudantes são associados ou suas famílias no STR de suas regiões. No que se refere aos serviços já utilizados, a maioria associada destacou o atendimento médico e jurídico apenas, participação em Eventos e Reuniões foi positiva para seis estudantes. Os demais estudantes que não são associados não demonstraram nenhum interesse em se vincular, seus argumentos decorrem pela falta de benefícios que os STR's disponibilizam em suas regiões. Ainda, os estudantes destacaram a participação em Eventos do STR dentro da Escola, para muitos o único que já realizou, pois, a EFA fomenta a parceria com essas instituições.

Entende-se que estar vinculado a instituições que possuem como missão o desenvolvimento rural permite que os agricultores estejam inseridos em projetos alternativos, que promovam a sustentabilidade do meio rural, pela construção solidária e trabalho cooperativo.

\section{Os Caminhos de Aprendizagens pelas Casas Familiares Rurais:}

Havendo consciência da importância dos Instrumentos Pedagógicos da Pedagogia da Alternância para a formação integral dos estudantes e o desenvolvimento do meio, via construção do conhecimento, a equipe gestora da Associação Regional das Casas Familiares Rurais do Rio Grande do Sul (ARCAFAR/SUL) convidou os monitores, professores, gestores e funcionários de todas as Casas Familiares Rurais do Estado para um Curso de Formação de Monitores. Este curso ocorreu nas dependências da sede da ARCAFAR/Sul e da Escola de Ensino Médio Casa Familiar Rural no município de Frederico Westphalen, nos dias 12 e 13 de julho de 2018. A participação neste curso foi possível pela realização do estágio de docência em espaço não escolar na Federação dos Trabalhadores da Agricultura do Rio Grande do Sul (FETAG-RS) de um dos autores deste artigo.

Nestes dois dias de encontro foram estudados os conceitos e as metodologias dos Instrumentos Pedagógicos que as CFR's utilizam com maior ou menor grau de profundidade de acordo com as especificidades de cada região 
onde as CFR's estão inseridas. Assim sendo, a seguir será descrito as definições que foram apresentadas às equipes escolares e dialogada com suas aplicabilidades de acordo com a realidade encontrada na área de atuação da escola.

Após o Acolhimento com Mística realizado pela CFR's anfitriã e as apresentações pessoais, o diálogo foi iniciado com a explicação das características que identificam e constituem os quatro pilares da Pedagogia da Alternância nas Casas Familiares Rurais, os Meios (Alternância e Associação Local) que encaminham o Jovem (Família, Comunidade, meio Socioprofissional), para as Finalidades (Formação Integral e Desenvolvimento do Meio). Também a definição do processo educativo na Pedagogia da Alternância de acordo com o Trevisan (2018), o qual ministrou essa temática no curso de formação.

É um processo de construção do saber e não apenas apropriarse de um saber já existente: Saber não se transmite, se constrói de muitas formas diferentes; Acontece por etapas sucessivas; o adolescente aprende a partir de objetos concretos; São estágios progressivos cronológicos, por etapas; Acontece quando o jovem é envolvido diretamente; Acontece sobre coisas e fenômenos que têm sentido para o educando. Tem que ser uma resposta a perguntas feitas: Parte da pergunta e ajuda o jovem a questionar; Ajuda encontrar respostas significativas para as perguntas; Ajuda a aprender, cada um de forma diferente; Estimula a inteligência lógica, parte da experiência, depois reflete para entender a experiência; Afirma que o saber aparece na experiência refletida; Afirma que: verbalizar é escrever, é passar de um saber experimentado para o refletido! (TREVISAN, 2018, p. $04-05)$.

Destaca-se dessas instituições de ensino a valorização e resgate dos saberes de origem, da prática cotidiana de vida e do trabalho, e transmitida em geração. Atendendo assim as demandas das populações do campo por uma educação digna e contextualizada.

Após a discussão desta temática, foi analisado um dos principais documentos que rege o trabalho numa instituição de formação por alternância, o Plano de Formação, o qual representa uma estratégia de organização das alternâncias. É através dele que se articula, de forma mais coerente, os espaços 
e tempos de estudo nas CFR's com os espaços e tempos na família, comunidade, enfim, no meio socioprofissional.

O Plano de Formação organiza as atividades para cada espaço e tempo, assim, permite a realização de uma alternância integrativa, verdadeira, evitando a dissociação da prática com a teoria, do trabalho e das experiências da vida com o estudo e a reflexão na CFR. O Plano de Formação deve priorizar a vida e as experiências concretas e práticas, os conhecimentos populares, dentre outros aspectos e precisa ser avaliado e reconstruído permanentemente, buscando atender sempre as reais necessidades dos educandos, suas famílias e comunidades. (TREVISAN, 2018, p. 07 - 08).

A elaboração do Plano de Formação (PF) depende do envolvimento das famílias e comunidades, pois é através da Pesquisa Participativa do PF que surgem os Temas Geradores que constituirão a formação do estudante. O Tema Gerador, definido como o questionamento da realidade, também é base para o Plano de Estudo, os quais serão debatidos na sessão escolar.

Outro instrumento debatido foi o Contato Individualizado, o qual corresponde a Tutoria nas EFA's. Um atendimento individual do monitor com o estudante (orientando), para uma conversa de acolhimento e orientação. E em seguida a colocação em comum que é a sistematização do plano de estudo feito pelos estudantes no momento socioprofissional.

Os cadernos que acompanham a formação dos estudantes das CFR's são semelhantes à sua irmã EFA, os Cadernos da Alternância e da Realidade. O Caderno da Alternância traz os trabalhos que devem e foram desenvolvidas pelo estudante na escola e no seu meio socioprofissional e também as observações dos pais, como meio de comunicação com a escola. O Caderno da Realidade é considerado o caderno da vida do estudante, pois possibilita uma reflexão da vida, baseado nos planos de estudos sob orientação dos Monitores e da bibliografia escolar, bem como nas comparações na colocação em comum, experiências e pesquisas que estes vivenciam.

Nas CFR's são oferecidos Curso de Formação para os estudantes, em complementaridade aos conteúdos programáticos do tema gerador e das áreas do conhecimento no decorrer da semana de forma interdisciplinar, com aulas teóricas e práticas, em sua maioria, são cursos de técnicas agrícolas, oferecido 
por parceiros da escola. Assim sendo, foram revisadas quais parcerias ainda era interessante manter e as temáticas específicas a serem trabalhadas em cada região e as que poderiam ser compartilhadas entre as escolas. A capacidade de questionamento e senso crítico dos estudantes é estimulada a partir de Visitas de Estudo que visa o conhecimento de novas realidades, novas técnicas, confrontando realidades diferentes da própria e a possibilidade de realizar intercâmbio com outras pessoas e comunidades. Este instrumento demonstra ser bastante necessário para a formação dos estudantes que vivem em comunidades muito afastadas e isoladas da sede do município.

Para subsidiar as mudanças que os estudantes propõem no seu meio socioprofissional, é disponibilizado a esses espaços e métodos de experiências dentro do território escolar, para que consigam aprimorar e aplicar seus conhecimentos para assim provocar melhorias na propriedade familiar e comunidade de origem, comprovando que transições no sistema produtivo são possíveis. Na Pedagogia da Alternância o método de avaliação é fundamental para garantir o sucesso do processo educativo. Ele fomenta o espírito e trabalho em equipe, e realizado no decorrer do processo, deve ter o envolvimento de todos os atores e jamais deve ser entendida como atribuir uma nota. Como traz o professor Trevisan na apresentação durante o curso.

No primeiro ano: Possibilidade de conversar sobre a sua realidade, conhecer-se e valorizar seu plano de estudo. Capacidade de conversar sobre suas atividades profissionais. [...] Elaboração de planos de estudo. Iniciativa em experiências.

No segundo ano: Verificar métodos básicos que desenvolvam a curiosidade e o questionamento, dando-lhes capacidade de assumir responsabilidades na comunidade. [...] Capacidade de assumir responsabilidades. Realizar atividades por iniciativa própria. Espírito de curiosidade. Desenvolvimento da capacidade de resolver problemas concretos. No terceiro ano: Avaliar a capacidade de comprometer-se, de descobrir uma atividade e desenvolvê-la na sua totalidade. Solucionar problemas concretos da vida, observar sua capacidade em utilizar as áreas do conhecimento e a capacidade de assumir projeto de vida profissional. Conhecimento que o jovem tem de sua exploração agrícola. [...] Se o jovem tem capacidade de descobrir uma atividade agrícola num todo. Assumir um projeto de vida profissional. Sua capacidade de fazer síntese. Capacidade de utilizar o conhecimento das disciplinas e se 
percebe a existência das mesmas em suas explorações. (TREVISAN, 2018: p 105 - 108).

Para finalizar, foi debatido sobre o Projeto Profissional de Vida do Jovem (PPVJ), que é o trabalho final de formação, onde o estudante, juntamente com sua família e comunidade, devem propor um projeto de transformação para sua realidade, a partir de todas as análises realizadas no decorrer desses três anos de formação, que seja sustentável, permita a autonomia e independência da família e seja rentável a comunidade.

Além do debate sobre os Instrumentos Pedagógicos foram abordadas outras temáticas referentes à vida no campo, pela educação e a conjuntura que estávamos vivendo. O professor da CFR, Zuchi, também é Padre, dissertou sobre a "Formação do professor e sua importância para além da sociedade capitalista", onde trouxe a reflexão da prática docente para a formação cidadã. Outra palestra realizada foi o "Contexto da Agricultura Familiar no RS: limites e possibilidades" debatido pelo professor Pelegrini, o qual tivemos um apanhado histórico da região de atuação das escolas e quais consequências presencia-se ainda hoje. E para finalizar o encontro, foi realizada reunião com todos os docentes das CFR's, divididos por áreas do conhecimento para compartilhar as possibilidades de trabalhos e dialogar sobre dificuldades que encontravam nas suas realidades, socializando essa experiência no encerramento do Curso de Formação.

\section{Considerações Finais}

A reflexão sobre as percepções dos estudantes das CEFFA's e as diretrizes que compõe o trabalho dessas instituições serviram para demonstrar a importância desse modelo educacional inovador, enquanto estratégia educativa, para as populações do campo. Permitindo a construção do conhecimento a partir do diálogo dos saberes originários e os conhecimentos científicos curriculares, a diminuição do êxodo rural e o desenvolvimento do meio sociocultural das comunidades onde estas instituições estão inseridas, respondendo assim à questão orientadora dessa pesquisa. 
Quando são apresentados no artigo, as compreensões dos estudantes sobre os inúmeros modelos de agriculturas, balizados nos seus conhecimentos socialmente construídos e nos autores referenciados, percebe-se os desafios que essas instituições de ensino ainda têm a superar. Mas também, glorifica-se o trabalho que já vem sendo construído na quebra do paradigma da agricultura convencional em detrimento aos modelos de produção mais sustentáveis de alimentos. E assim, permitindo que seus estudantes promovam projetos de desenvolvimento rural para a transição agroecológica.

Essas considerações foram viáveis devido as possibilidades de imersão nessas realidades educacionais, pela dinâmica de ensino da Alternância do curso de licenciatura em Educação do Campo. O qual subsidiou pedagógica e metodologicamente vivenciar essas experiências, permitindo aprender em Alternância, conhecer as histórias e lutas dos movimentos sociais do campo, e sua importância para a educação brasileira e o desenvolvimento rural.

Pensar a Educação do Campo, seja no ensino superior pelas licenciaturas ou na educação básica na rede CEFFA's, é fomentar outras perspectivas educacionais que entendam as populações do campo como protagonistas do seu desenvolvimento e ainda promover alternativas de agriculturas mais sustentáveis em detrimento ao modelo agrícola convencional.

Destaca-se a Pedagogia da Alternância com a concretização de seus Instrumentos Pedagógicos como fundamental para a efetivação da construção do conhecimento, tornando a aprendizagem significativa ao estudante, pois parte de suas próprias realidades em consonância ao conhecimento técnico cientifico dos Monitores, professores e parceiros.

Esse modelo educacional desenvolve-se plenamente nas experiências estudadas nessa pesquisa. Seja adaptando suas ferramentas de ensino de acordo com a realidade que é confrontada, realizando o movimento de Alternância em harmonia ao período agrícola de cada região e oferecendo aos seus estudantes a possibilidade de transformação social.

Essas instituições irmãs, se expressam de formas diferentes, pois estão em regiões distintas no Estado e acolhem uma diversidade cultural nas escolas. Elas mantêm a rigorosidade do desenvolvimento dos Instrumentos Pedagógicos 
que legitimam a Pedagogia da Alternância, mas realizam a adaptação desses para o público que acolhem, os estudantes, suas famílias e as comunidades que estão inseridas. Muitos Instrumentos Pedagógicos tem nomes diferentes, mas possuem o mesmo objetivo, como é o caso da Tutoria nas EFA's e do Contato Individualizado nas CFR's que servem para o acompanhamento mais próximo do estudante, mantendo em seus pilares a formação integral desses jovens que é um dos objetivos originários desse modelo de educação.

A Pedagogia da Alternância foi destacada pelos estudantes considerando ser o sistema educacional mais adequado à realidade do campo. Permitem aos estudantes entrelaçar os diferentes saberes e manter o vínculo com a propriedade familiar e seus desafios. Este processo permite a possibilidade da sucessão rural e a ressignificação dos seus valores e possibilitando processos de produção mais sustentáveis de alimentos.

Convém mencionar que as considerações aqui elencadas não possuem o caráter de encerrar a discussão, mas sim de subsidiar mais pesquisas e o aprofundamento sobre a temática.

\section{Referências Bibliográficas}

BARROS, A. J. P.; LEHFELD N. A. S. Projeto de pesquisa: propostas metodológicas. Petrópolis, RJ, Vozes, 1994.

BORDENAVE, J. D.; Estratégias de ensino-aprendizagem. Vozes, 1977.

CALDART, R. S.; Educação do Campo. In: Dicionário da Educação do Campo. Caldart, R. S. et al. (Org.). Rio de Janeiro, São Paulo: Escola Politécnica de Saúde Joaquim Venâncio, Expressão Popular, 2012.

CAPORAL, F. R.; PETERSEN, P. Agroecologia e políticas públicas na América Latina: o caso do Brasil. Agroecologia, v. 6, p. 63-74, 2012.

COSTA, J. P. R.; Escola Família Agrícola de Santa Cruz do Sul - EFASC: uma contribuição ao desenvolvimento da região do Vale do Rio Pardo a partir da pedagogia da alternância. Dissertação (Mestrado em Desenvolvimento Regional). Universidade de Santa Cruz do Sul, 2012.

CIPPA EFA Serra Gaúcha. Cartilha dos Instrumentos Pedagógicos da Pedagogia da Alternância da Escola Família Agrícola da Serra Gaúcha. EFA Serra Gaúcha, Caxias do Sul, 2013. 
FECOVINHO, Federação das Cooperativas Vinícolas do Rio Grande do Sul. Viticultura Biodinâmica na Serra Gaúcha: um projeto piloto. Instituto Brasileiro do Vinho, 2016.

FERREIRA, A. G.; A formação através da Pedagogia da Alternância em Agroecologia: um estudo de caso da Escola Família Agrícola de Santa Cruz do Sul, RS. 2014. 99 f. Dissertação (Mestrado em Extensão Rural) - Universidade Federal de Santa Maria, Santa Maria, 2014.

FREIRE, P.; Educação e Mudança. São Paulo: Paz e Terra, 1999.

GIL, A. C.; Métodos e Técnicas de Pesquisa Social. $6^{\circ}$ ed. São Paulo: Atlas, 2008.

JOVCHELEVICH, P.; Rendimento, qualidade e conservação pós-colheita de cenoura (Daucus carota L.), sob cultivo biodinâmico, em função dos ritmos lunares. Dissertação (Mestrado). Faculdade de Ciências Agronômicas. Universidade Estadual Paulista. Botucatu, 2007.

MARCONDES, N. A. V., BRISOLA, E. M. A.; Análise por Triangulação de Métodos: um Referencial para Pesquisas Qualitativas. Revista UNIVAP, v. 20, n. 35, jul. 2014, p. $201-208$.

NASCIMENTO, C. G.; A Educação Camponesa como espaço de resistência e recriação da cultura: um estudo sobre as concepções e práticas educativas da Escola Família Agrícola de Goiás - EFAGO. Dissertação de Mestrado (Educação). Campinas: FE/Unicamp, 2005.

NOSELLA, P.; Origens da pedagogia da alternância no Brasil. Vitória: Edufes, 2014.

PESSOTTI, A. L.; Escola da Família Agrícola: uma alternativa para o ensino rural. Rio de Janeiro, 1978. 194p. Dissertação (Mestrado). Fundação Getúlio Vargas, IESAE. 1978.

PPCGLedoc. Projeto Pedagógico do Curso de Graduação Licenciatura em Educação do Campo, Universidade Federal do Rio Grande do Sul, Curso de Graduação Licenciatura em Educação do Campo - UFRGS. 2013.

LE COQ, J. F. et al.; Conceptos de agroecología y marco analítico. In: SABOURIN, E. [et al.]. Org. Políticas públicas a favor de la agroecología em América Latina y El Caribe. Porto Alegre: Evangraf / Criação Humana, Red PPAL: FAO, 2017.

SILVA, E. L; MENEZES, E. M.; Metodologia da pesquisa e elaboração de dissertação. Revista Atual, Florianópolis: Laboratório de Ensino a Distância da UFSC, 2001. Disponível: http://projetos.inf.ufsc.br/arquivos/Metodologia.pdf. Acesso em: 14 de junho de 2019. 
SOBREIRA, M. F. C.; SILVA, L. H. Vida e construção do conhecimento na Pedagogia da Alternância. Revista Eletrônica de Educação, v. 8, n. 2, 2014. p. 212-227.

TREVISAN, F.; Instrumentos da Pedagogia da Alternância. Palestra do Curso Formação de Monitores, 2018, Associação Regional das Casas Familiares Rurais do Rio Grande do Sul (ARCAFAR/SUL); Escola de Ensino Médio Casa Familiar Rural de Frederico Westphalen. Apresentação no evento, 2018.

\section{Sobre os autores}

\section{Aline Guterres Ferreira}

alinegufe@gmail.com

Zootecnista (Universidade Federal de Santa Maria), Licenciada em Educação do Campo - Ciências da Natureza (Universidade Federal do Rio Grande do Sul). Especialista em Educação Ambiental e Mestra em Extensão Rural (UFSM). Doutoranda no Programa de Pós-graduação em Educação em Ciências: Química da vida e saúde (UFRGS).

\section{José Vicente Lima Robaina}

joserobaina1326@gmail.com

Professor do curso de Licenciatura em Educação do Campo - Ciências da Natureza. Professor do Programa de Pós Graduação em Educação em Ciências: Química da vida e saúde. Professor do Departamento de Ensino e Currículo da Faculdade de Educação da UFRGS - Campus Porto Alegre/RS.

\section{Alberto Bracagioli Neto}

abracagioli@gmail.com

Professor do Departamento de Horticultura e Silvicultura da Faculdade de Agronomia-UFRGS, Professor da Licenciatura em Educação no Campo e Professor Colaborador do Programa de Pós-Graduação em Desenvolvimento Rural (PGDR-UFRGS).

\section{José Geraldo Wizniewsky}

zecowiz@gmail.com

Professor da Universidade Federal de Santa Maria (UFSM), do Departamento de Educação Agrícola e Extensão Rural e professor no Programa de Pósgraduação em Extensão Rural. Professor no Curso de Licenciatura em Educação do Campo e Agroecologia (UFSM). 